\title{
Expression of Amphiphysin I, an Autoantigen of Paraneoplastic Neurological Syndromes, in Breast Cancer
}

\author{
Scott Floyd, ${ }^{1}$ Margaret Husta Butler, ${ }^{1}$ Ottavio Cremona, ${ }^{1}$ \\ Carol David,' Zachary Freyberg,' Xiaomei Zhang, ${ }^{1}$ \\ Michele Solimena, ${ }^{2}$ Akira Tokunaga, ${ }^{3}$ Hideki Ishizu, \\ Kimiko Tsutsui, ${ }^{3}$ and Pietro De Camilli ${ }^{1}$
}

${ }^{1}$ Howard Hughes Medical Institute, Department of Cell Biology and

${ }^{2}$ Department of Medicine, Yale University School of Medicine, New

Haven, Connecticut, U.S.A.

${ }^{3}$ Third Department of Anatomy and ${ }^{4}$ Department of Neuropsychiatry, Okayama University Medical School, Okayama, Japan

Communicated by V. T. Marchesi. Accepted November 24, 1997.

\begin{abstract}
Amphiphysin I is a $128 \mathrm{kD}$ protein highly concentrated in nerve terminals, where it has a putative role in endocytosis. It is a dominant autoantigen in patients with stiff-man syndrome associated with breast cancer, as well as in other paraneoplastic autoimmune neurological disorders. To elucidate the connection between amphiphysin I autoimmunity and cancer, we investigated its expression in breast cancer tissue. We report that amphiphysin I was expressed as two isoforms of 128 and $108 \mathrm{kD}$ in the breast cancer of a patient with anti-amphiphysin I antibodies and paraneoplastic sensory neuronopathy. Amphiphysin I was also detectable at vari-
\end{abstract}

able levels in several other human breast cancer tissues and cell lines and at low levels in normal mammary tissue and a variety of other non-neuronal tissues. The predominant amphiphysin I isoform expressed outside the brain in humans is the $108 \mathrm{kD}$ isoform which represents an alternatively spliced variant of neuronal amphiphysin I missing a 42 amino acid insert. Our study suggests a link between amphiphysin I expression in cancer and amphiphysin I autoimmunity. The enhanced expression of amphiphysin I in some forms of cancer supports the hypothesis that amphiphysin family members may play a role in the biology of cancer cells.

\section{Introduction}

Amphiphysin I is an $\mathrm{SH} 3$ domain-containing protein expressed at high levels in the nervous system $(1,2)$. It is concentrated in axon terminals where it has a putative role in synaptic vesicle endocytosis (2-4) and growth cone dynamics (5). Outside the nervous system, it was reported to have a restricted distribution $(1,6)$.

Address correspondence and reprint requests to: Dr. Pietro De Camilli, Department of Cell Biology, Howard Hughes Medical Institute, 295 Congress Ave., New Haven, CT 06510, U.S.A. Phone: (203) 737-4465; Fax: (203) 737 1762; E-mail: pietro.decamilli@yale.edu
Amphiphysin I has been identified as an autoantigen in human neurological paraneoplastic autoimmune diseases, often in association with breast cancer (6-9). The proposed scenario for these paraneoplastic syndromes is that (i) neoplastic transformation of a non-neuronal tissue results in ectopic expression of a neuronal protein in that tissue, and (ii) ectopic expression leads to anti-nervous system autoimmunity and neurological disease $(10,11)$. Autoantigen expression in cancer has been reported in many cases $(10,11)$, and it is possible that autoantigen expression may be involved in the biology of cancer. 
Studies on members of the amphiphysin family have suggested a relationship between this protein family and the regulation of cell proliferation. Two proteins sharing blocks of homology with amphiphysin, Rvs161 and Rvs167, are present in Saccaromyces cerevisiae (12-15). The $R V S$ (reduced viability upon starvation) phenotype, which led to the identification of genes encoding these proteins, suggests the loss of regulatory feedback between availability of nutrients in the medium and growth $(12,13)$. A homologue of amphiphysin I, amphiphysin II, has recently been described in mammalian cells. Amphiphysin II undergoes extensive alternative splicing, resulting in multiple isoforms with different tissue and subcellular distributions (16-22). One of these isoforms, BIN1, was reported to interact with the MYC proto-oncogene and to act as a negative regulator of cell proliferation (17). Another isoform was found to interact with the proto-oncogene cABL (23). It is therefore of interest to characterize amphiphysin I expression in cancer cells.

We show here that amphiphysin I is more widely expressed in non-neuronal tissues than previously reported, although its concentration in non-neuronal tissues is much lower than in brain. We also demonstrate enhanced expression of amphiphysin I isoforms in several breast cancer tissues and cell lines, including the tissue of a patient with paraneoplastic sensory neuronopathy.

\section{Materials and Methods}

\section{Antibodies}

Rabbit polyclonal antibodies directed against amphiphysin I (CD5) (14), amphiphysin I and II (CD9) (19), synaptojanin (24), dynamin (25), synapsin I (26), and synaptophysin (27) were previously described. Anti-vimentin monoclonal antibodies were obtained from BoehringerMannheim. Human anti-amphiphysin I positive sera from paraneoplastic patients were previously described $(6,7)$. Mouse monoclonal antibodies were generated as described $(28,29)$ using full-length His-tagged human amphiphysin I as the immunogen. Initial screening of hybrid clones was performed by Western blotting. The strongest 28 clones were selected and analyzed for their reactivity with amphiphysin I fragments expressed as GST fusion proteins in the pGEX-2T vector (Pharmacia) as previously described (14) (see also Fig. 4). The reactivity of the individual clones was as follows: Fragment 1: clones AIl, AI2, AI6, AI7, AI8, AI9, AI17, AIl8, AI19, AI20,
AI2 1, AI22, AI23; Fragment 2: clones AI15, AI16, AI24, AI25, AI26; Fragments 2 and 3: clones AIl 1, AI12, AI13, AI27, AI28; Fragment 3: clone AIl4; Fragment 4: clone AI5; Fragment 5; clones AI3, AI4, AIlo.

\section{Human and Rat Tissues}

Breast tissue from Patient 692 was collected at surgery and immediately quick-frozen in liquid $\mathrm{N}_{2}$. Other frozen human tissues were obtained from the Critical Technologies Service at Yale University and from the National Breast Cancer Tissue Resource of the San Antonio SPORE (Specialized Program of Research Excellence). Fresh rat tissues were obtained from euthanized animals and quickfrozen in liquid $\mathrm{N}_{2}$. Tissues were pulverized under liquid $\mathrm{N}_{2}$ and solubilized ( $4 \mu \mathrm{l} / \mathrm{mg}$ tissue) in buffer A (150 mM NaCl, $10 \mathrm{mM}$ Hepes (pH 7.5), 2\% SDS, plus $4 \mu \mathrm{g} / \mathrm{ml}$ each of pepstatin, aprotinin, leupeptin, and phenylmethylsulfonyl fluoride).

\section{Cell Culture and Affinity Chromatography}

Human breast cell lines Hs578T, Hs578Bst, MCF7, MBA-MD-453, MDA-MB-231, SK-BR3, and MCF10 were either purchased from the American Type Culture Collection or obtained from Dr. David Stern (Yale University) and maintained as described earlier (30). Protein extracts for SH3 affinity-chromatography were prepared by lysing cells at $4^{\circ} \mathrm{C}$ in buffer $A$ in which $2 \%$ SDS had been replaced with $2 \%$ Triton $\times 100$ at $4^{\circ} \mathrm{C}$. The extract was then clarified at $100,000 \times g$ for 30 min. Affinity-chromatography of the extract on GST and GST fusion proteins comprising the proline-rich domain of human dynamin I (DynPRD 751-848) or a truncated form of this domain missing the amphiphysin I binding site (DynPRD 751-832) was performed as described earlier (25).

\section{cDNA Cloning}

Total RNA was extracted from approximately $10^{10} \mathrm{Hs} 578 \mathrm{~T}$ cells using the guanidinium thiocyanate method (31) and a random and oligo dT primed cDNA library in $\lambda$ ZAPII phage vector was constructed (Stratagene custom library service). A probe corresponding to bp 1573-2163 of the human brain amphiphysin I sequence (accession \#U07616) (15) was constructed by polymerase chain reaction (PCR) from the human amphiphysin I complete cDNA using primers (forward) 5'-CTGCCGGGGAAGGAGTAAGTTT-3' 
and (reverse) 5'-CCTAATCTAAGCGTCGGGTGA AGT-3'. This probe was radioactively labeled by primer direct labeling (32) and used to screen $1 \times 10^{6}$ plaques of the custom library. Five positive clones were identified (clones 1.4, 3.3, 3.4, 16.1, 16.3). Clone 3.4 was sequenced with an ABI automatic sequencer (Keck Biotechnology Foundation, Yale University) and found to contain a full-length coding sequence and untranslated $5^{\prime}$ and $3^{\prime}$ regions (accession \#AF034996).

\section{$R T-P C R$}

Total RNA was extracted from either approximately $10^{10} \mathrm{Hs} 578 \mathrm{~T}$ cells or $100-300 \mathrm{mg}$ of human tissue (obtained from the Yale Critical Technology service) using the guanidinium method (31). The extracted total RNA was then reverse transcribed using Superscript II reverse transcriptase (Gibco), treated with RNAse, and purified with Glass Max columns (Gibco), and the resulting cDNA was amplified by PCR using overlapping primers designed to span the length of amphiphysin I. The primer sequences were as follows and were located in the following positions of the human amphiphysin I complete cDNA (accession \# U07616) (15): \#1 Forward 5'-TATGGGCGGGAAGATGTGAAAATG-3' bp 1573-1594, Reverse 5'-CGGGAGACGCAGGTGC TAATGTAT-3' bp 2163-2140; \#2 Forward 5'CCAGCACGGCCTCGGTCAC-3' bp 936-954,

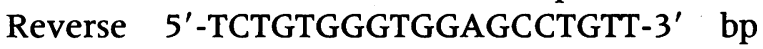
1394-1371; \#3 Forward 5'-AGCCGGCTTCTGGT GGTTCATT-3' bp 1252-1273, Reverse 5'-CGCG TCCTCGGTGGTCTCC-3' bp 1790-1772; \#4 Forward 5'-CTGCCGGGGAAGGAGTAAGTTT-3' bp 1573-1594, Reverse 5'-CCTAATCTAAGCGTCG GGTGAAGT-3' bp 2163-2140; \#5 Forward 5'ATGGGCGGGAAGATGTGAAAATGG-3' bp 343366, Reverse 5'-TCTGTGGGTGGAGCCTGTT-3' bp 1375-1357; \#6 Forward 5'-TCACCCCGACA AAGGAACT-3' bp 1000-1018, Reverse 5'-TAA AAACCCCGTAACTGAGC-3' bp 2205-2186. Standard PCR techniques were employed. Amplified bands were analyzed by $1 \%$ agarose gel electrophoresis and ethidium bromide staining. Bands showing a molecular weight different from the predicted were purified from the gel and directly sequenced as above.

\section{In Vitro Translation}

cDNA clones in the Bluescript vector (Stratagene) were transcribed and translated in vitro using the TnT Coupled Reticulocyte Lysate sys- tem (Promega). One microgram of DNA was included in each reaction. A 5- $\mu$ l aliquot of this reaction was then analyzed by Western blot.

\section{Miscellaneous Procedures}

Proteins were assayed by the BCA method (Pierce Pharmaceuticals). SDS-PAGE and Western blotting were carried out according to the method of Laemmli (33) and Towbin et al. (34), respectively.

\section{Results}

Amphiphysin I Autoimmunity in a Patient with Breast Cancer and Sensory Neuronopathy

A search for the presence of autoantibodies in a 44-year-old female patient with breast cancer and paraneoplastic sensory neuronopathy $(\mathrm{Pa}-$ tient 692) led to the identification of high-titer anti-amphiphysin I antibodies in her serum and cerebrospinal fluid. The clinical history of this patient will be described in more detail in a separate case report (K. Tsutsui, unpublished observations). The amphiphysin I band was the only band recognized in rat or human brain by both the serum and the cerebrospinal fluid of the patient (Fig. 1 and data not shown). Autoantibodies of this patient did not recognize amphiphysin II in Western blots, as shown by a comparison with the labeling pattern produced by the CD9 rabbit serum (19) which recognizes both amphiphysin I and II (Fig. 1A). The autoantibodies of the patient were directed primarily against the $\mathrm{COOH}$ terminal region of the amphiphysin I (Fig. 1B), which is in agreement with results obtained previously with other paraneoplastic patients (ref. 14 and data not shown). We note that, whereas all sera of paraneoplastic patients have in common their reactivity with the $\mathrm{COOH}$ terminal region of amphiphysin I, (ref. 14 and this study), this is not the immunodominant portion of the molecule as revealed by epitope mapping of a panel of 30 mouse monoclonal antibodies (data not shown and see Materials Methods), which suggests that the autoimmune response to amphiphysin I is not simply an exaggerated response to an immunodominant epitope.

\section{Amphiphysin I Expression in Breast Cancer Tissue of Patient 692}

A sample of cancer tissue from Patient 692 was obtained at surgery and analyzed for the expression of amphiphysin I immunoreactivity by 

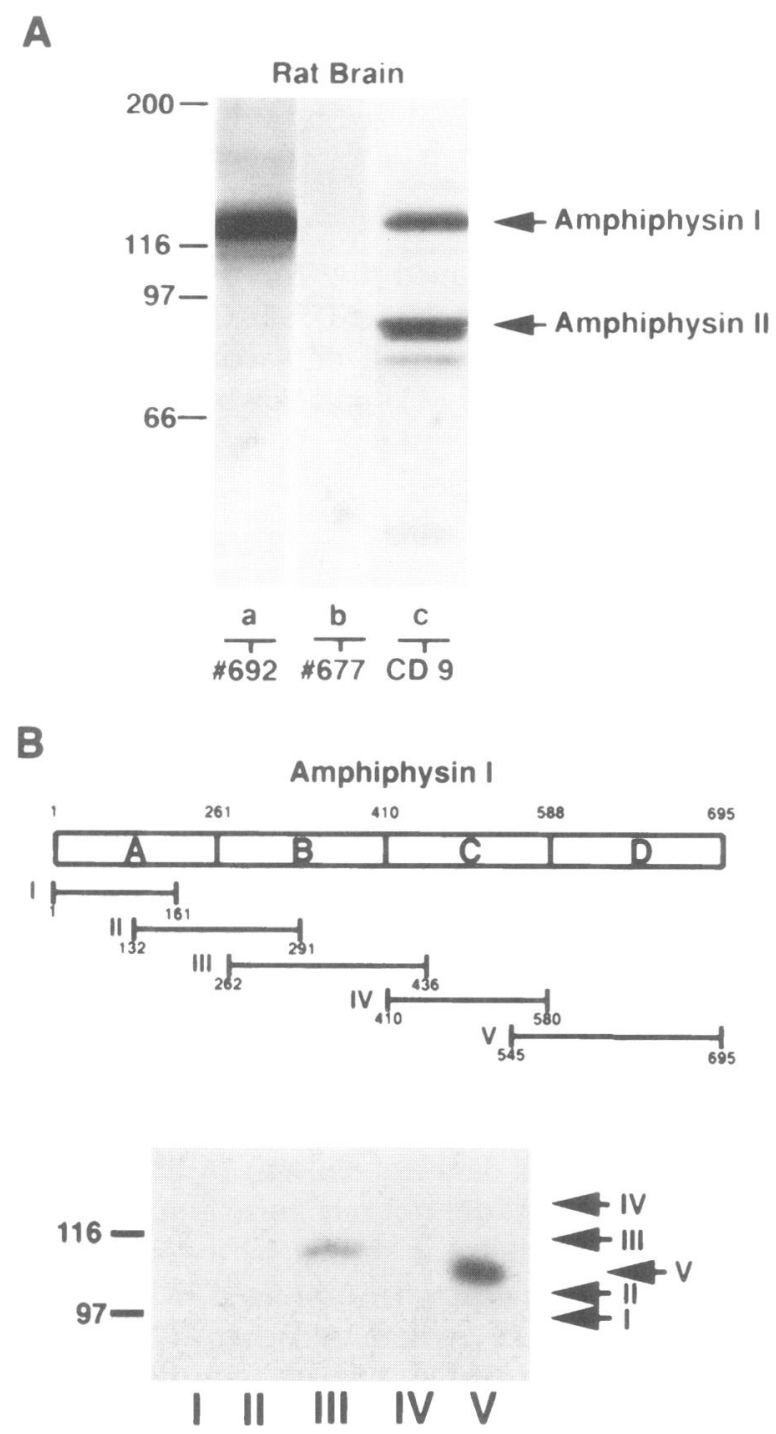

Fig. 1. Identification of anti-amphiphysin I autoimmunity in the serum of a patient with paraneoplastic sensory neuronopathy (Patient 692). (A) Total rat brain homogenate was analyzed by Western blotting with the following sera: (a) serum of the patient, (b) serum of a normal control patient, (c) rabbit serum CD9 that recognizes amphiphysin I and II (19). (B) The epitope specificity of the autoantibodies from Patient 692 was mapped by Western blot using GST fragments corresponding to the overlapping fragments of amphiphysin I depicted. Most autoantibodies reacted with fragment $V$, with a weaker response to fragment III. Electrophoretic mobility of the fragments is indicated at right.

Western blotting. A rabbit antiserum raised against recombinant human amphiphysin I (14) recognized two protein bands at 128 and $108 \mathrm{kD}$ in the cancer tissue (Fig. 2). The $128 \mathrm{kD}$ band precisely comigrated with neuronal amphiphysin I (Fig. 2). The $108 \mathrm{kD}$ band was recognized by all anti-amphiphysin I antibodies tested, including the serum of Patient 692 and monoclonal antibodies reacting with five different fragments spanning the entire length of the protein (Fig. 4 and data not shown). Thus the $108 \mathrm{kD}$ band (a doublet in many gels) is immunologically indistinguishable from the $128 \mathrm{kD}$ amphiphysin I band and most likely represents an amphiphysin I isoform. None of several anti-amphiphysin II antibodies tested reacted with the $108 \mathrm{kD}$ band, demonstrating that this band is not an amphiphysin II isoform (not shown).

\section{Amphiphysin I Expression in Mammary Tissue and Cell Lines}

Amphiphysin I immunoreactivity had not been detected previously in mammary tissue $(7,8)$. The detection of amphiphysin I in the breast tissue of Patient 692 prompted us to reinvestigate its expression in other specimens of normal and neoplastic human mammary tissue. We searched for amphiphysin I immunoreactivity in 6 cell lines derived from neoplastic human mammary tissue and 2 cell lines derived from histologically normal tissue. One of the cancer cell lines, Hs578T (30), expressed high levels of the $108 \mathrm{kD}$ amphiphysin I immunoreactive band (Fig. 3A,B). This band was recognized by polyclonal antibodies directed against amphiphysin I (Fig. 3) as well as by monoclonal antibodies directed against the five distinct regions of the protein (Fig. 4, lanes c). Lower levels of the 108 $\mathrm{kD}$ band were detected in the cell line Hs578Bst, which was derived from histologically normal tissue outside the margin of the cancer from which the cell line Hs578T was derived (30) (Fig. 3A). Other cell lines expressed amphiphysin I only at the limit of detectability. Neither the cancer tissue of Patient 692 nor the Hs578T cell line expressed elevated levels of synaptojanin I, dynamin I, and synapsin I, which suggests that the presence of amphiphysin I in the cell line and tissues was not due to neuroendocrine differentiation (Fig. 3C and data not shown). The expression of amphiphysin I in breast cell lines rules out the possibility that amphiphysin I expression in mammary tissue can be attributed to the presence of peripheral nerves.

We also searched for amphiphysin I immunoreactivity in normal and neoplastic human mammary tissues. We detected amphiphysin I in all tissues examined, which included 14 histologically normal breast tissues, 40 ductal, and 10 nonductal breast adenocarcinomas (Figs. 5, 6, 
2

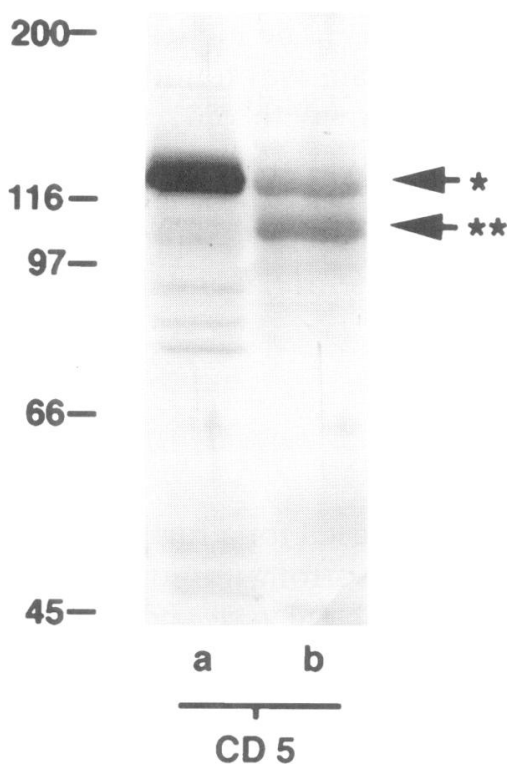

$3 \mathrm{~A}$
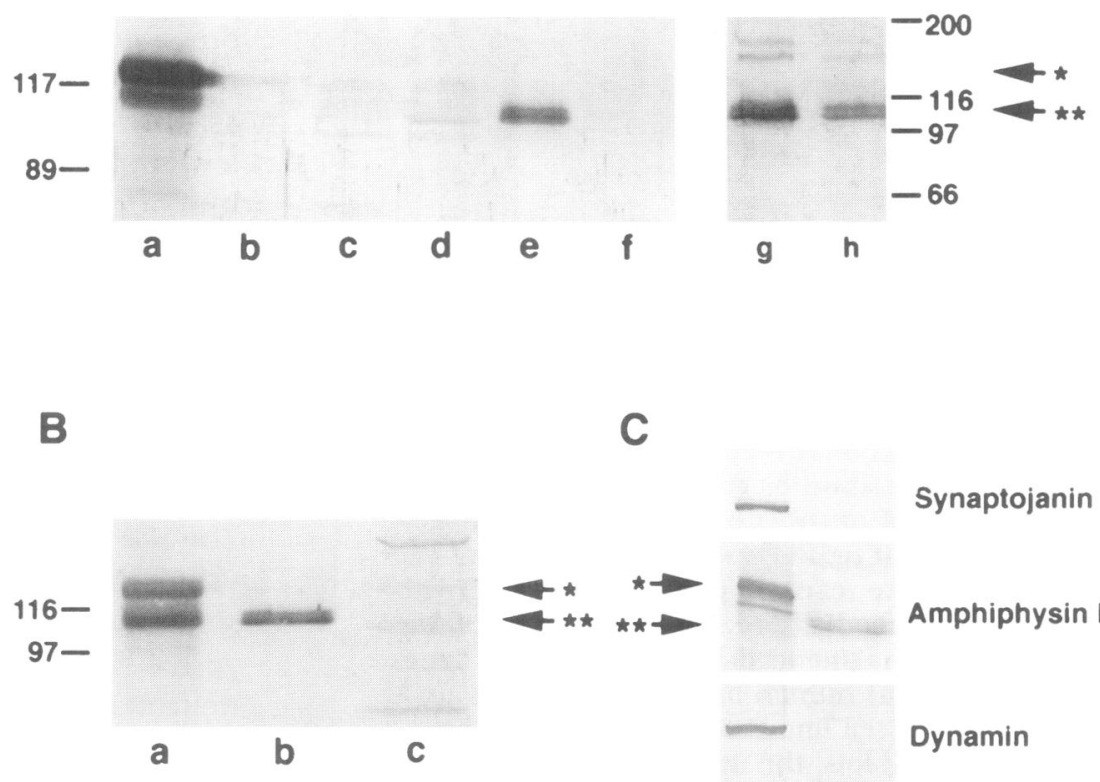

Synaptojanin

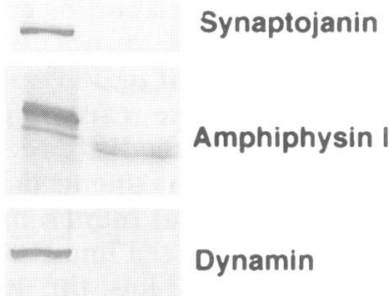

Synapsin
Fig. 2. Detection of amphiphysin I immunoreactivity in the cancer tissue of Patient 692. Total homogenates of human brain (a) and of the cancer tissue from Patient 692 (b) were analyzed by Western blotting using the anti-amphiphysin I rabbit serum $\mathrm{CD} 5$ as a probe. Brain contained a single 128 $\mathrm{kD}$ amphiphysin I immunoreactive band (one asterisk), whereas the cancer tissue contained both this band and a lower immunoreactive band of about $108 \mathrm{kD}$ (two asterisks). Total protein loading was as follows: $a, 100 \mu \mathrm{g} ; \mathrm{b}, 35 \mu \mathrm{g}$.

Fig. 3. Expression of amphiphysin I immunoreactivity in human cell lines derived from normal and neoplastic breast tissue. (A) Total protein homogenates of human brain $(10 \mu \mathrm{g})$ or of human cell lines $(20 \mu \mathrm{g})$ were probed by Western blotting with the rabbit anti-amphiphysin I anti-

and data not shown). However, levels of amphiphysin I were generally higher in cancer than in normal mammary tissue. Figure 5 compares the distribution of amphiphysin I immunoreactivity in overexposed Western blots of the breast cancer cell line Hs578T (lane b), a human primary breast tumor sample (lane $c$ ), and five normal breast tissues samples (lanes $d-h$ ). Note that both the 128 and the $108 \mathrm{kD}$ bands are visible in all normal tissues whereas cancer tissues express predominantly the $108 \mathrm{kD}$ band. serum CD5. Lanes are as follows: (a) rat brain; (b) MDA-MB-453 breast cancer cell line; (c) MCF7 breast cancer cell line; (d) MDA-MB-231 breast cancer cell line; (e) Hs578T breast cancer cell line; (f) SK-BR3 breast cancer cell line; (g) Hs578T cell line; (h) Hs578Bst breast tissue cell line. (B) Western blotting with the CD5 antiserum of (a) the cancer tissue of Patient 692, (b) the Hs578T cell line, and (c) a normal breast tissue cell line (MCF-10A) demonstrating the identical electrophoretic mobility of the $108 \mathrm{kD}$ bands in the cell line and in the cancer tissue. (C) Total homogenates of (a) rat brain and of (b) the cell line Hs578T probed by Western blotting with antibodies directed against the neuronal proteins indicated. Ten micrograms of rat brain and 20 $\mu \mathrm{g}$ of cell extract were loaded in a and b, respectively. One and two asterisks point to the 128 and the $108 \mathrm{kD}$ bands, respectively.

Figure 6A shows an additional comparison of the breast cancer cell line Hs578T (lane b), three normal mammary tissue samples (lanes c-e), and nine breast cancer tissue samples (lanes $\mathrm{f}-\mathrm{n}$ ). In this blot, the small amount of amphiphysin I present in normal tissues is undetectable, while enhanced, although variable levels of immunoreactivity are visible in all cancer tissues. Lane $g$ contains the same cancer tissue as in lane c of Fig. 5 and serves therefore as an internal calibration of the two figures. Lane $n$ in Fig. 6 contains 


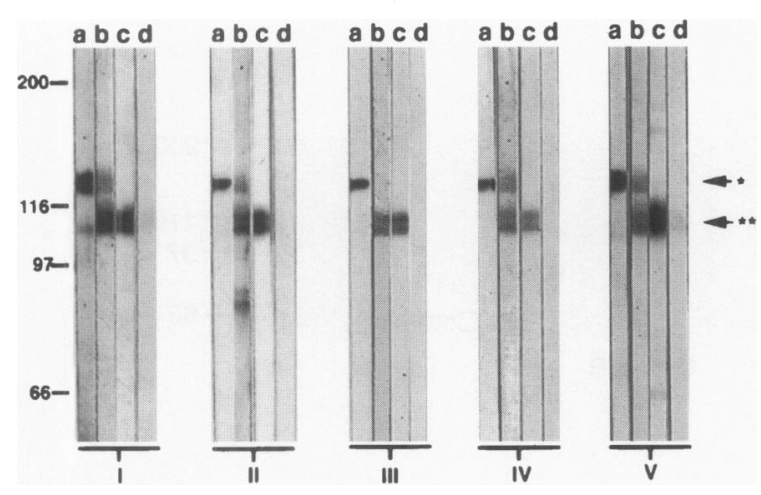

Fig. 4. Reactivity of the breast cancer tissue of Patient 692 and of the cell line Hs578T with 5 monoclonal antibodies directed against 5 distinct regions of amphiphysin I. Total homogenate proteins $(30 \mu \mathrm{g}$ for lanes a and $300 \mu \mathrm{g}$ for the other lanes) were reacted by Western blotting with monoclonal antibodies directed against each of the 5 amphiphysin I fragments depicted in Fig. 1B. Lanes are as follows: (a) human brain; (b) cancer tissue of Patient 692; (c) cell line Hs578T; and (d) cell line MCF7. In these blots, the upper $(128 \mathrm{kD}$, one asterisk) and lower ( $108 \mathrm{kD}$, two asterisks) amphiphysin I immunoreactive bands appear as doublets.

the cancer tissue of Patient 692 and is the only lane where both the 108 and the $128 \mathrm{kD}$ bands are visible. Figure 6B shows the lower portion of the blot shown in Fig. 6A probed with antivimentin antibodies to control for protein loading.

\section{Amphiphysin I Expression in Non-neuronal Tissues}

The identification of amphiphysin I immunoreactive bands in normal mammary tissue prompted us to reinvestigate the tissue distribution of amphiphysin I, which thus far was thought to be very restricted $(1,6)$. Monoclonal

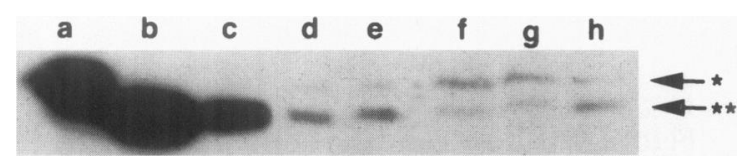

Fig. 5. Amphiphysin $I$ is present in human mammary tissues. Total protein homogenates of (a) human brain $(10 \mu \mathrm{g})$, (b) human breast cancer cell line Hs578T (100 $\mu \mathrm{g})$, (c) primary human breast tumor $(100 \mu \mathrm{g})$, and $(\mathrm{d}-\mathrm{h})$ normal human mammary tissues $(100 \mu \mathrm{g}$ each) were probed by Western blotting using a monoclonal antibody directed against domain V (see Fig. 1B) of amphiphysin I. One and two asterisks correspond to the 128 and $108 \mathrm{kD}$ amphiphysin I immunoreactive bands, respectively. antibodies directed against either the $\mathrm{COOH}$ terminal region (Fig. 7) or the NH2-terminal region (not shown) of amphiphysin I revealed its expression in all tissues tested. The highest level of expression outside the brain was found in testis as previously reported (6), with only very low levels of expression in other tissues. In several human non-neuronal tissues, the $108 \mathrm{kD}$ band was the predominant band, while amphiphysin I had a similar mobility in neuronal and non-neuronal tissues of the rat.

\section{Characterization of the $108 \mathrm{kD}$ Amphiphysin I Immunoreactive band}

The Hs578T cell line was used for a further analysis of the $108 \mathrm{kD}$ band. Its strong immunological similarity to the $128 \mathrm{kD}$ band (see above) suggested that it may represent a truncated form of neuronal amphiphysin I. Yet, a rabbit anti-serum (CD9) directed against amino acids 26-40 of amphiphysin I reacted with this band (not shown), which argues against an $\mathrm{N}$-terminal deletion. Likewise, the $108 \mathrm{kD}$ protein could be affinity purified by a GST fusion protein comprising the proline-rich region dynamin (Fig. 8), which is known to bind to the $\mathrm{COOH}$-terminal SH3 domain of amphiphysin (25), demonstrating the presence of a functional $\mathrm{SH} 3$ domain. Thus, a $\mathrm{COOH}$-terminal truncation is unlikely. To determine whether the $108 \mathrm{kD}$ isoform corresponds to an internal deletion of neuronal amphiphysin I, we cloned amphiphysin I from the Hs578T cell line.

A cDNA library of the Hs578T cell line was constructed and screened with an amphiphysin I-specific probe. Nucleotide sequencing of clone 3.4 isolated from the library (accession \#AF034996) revealed an open reading frame identical in sequence to that of neuronal amphiphysin I (accession \#U07616) (14), except for a 126 base pair deletion corresponding to bases 1383-1508 of the coding sequence (Fig. 9). Similar results were obtained when overlapping regions of the entire coding sequence of amphiphysin I were amplified from total RNA of the Hs578T cell line by a series of RT-PCR reactions (not shown). The 126 base pair deletion predicts a corresponding deletion of 42 amino acids, which is less than expected for the electrophoretic difference between the 128 and $108 \mathrm{kD}$ bands. However, amphiphysin I (128 kD isoform) is known to have an aberrantly low electrophoretic mobility (1) and the 42 amino acid deletion lies within the sequence previously 
A

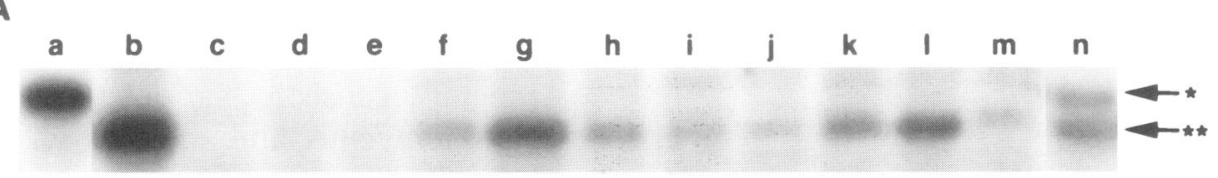

B

Fig. 6. Enhanced expression levels of amphiphysin $I$ in neoplastic human mammary tissues. (A) Total protein homogenate of (a) human brain $(10 \mu \mathrm{g})$, (b) Hs578T cell line (100 $\mu \mathrm{g})$, (c-e) normal human mammary tissues (100 $\mu \mathrm{g}$ each), (d-m) human primary human breast tumors (100 $\mu \mathrm{g}$ each), and (n) breast tumor from Patient 692 (75 $\mu \mathrm{g})$ was probed by Western blotting with an antiamphiphysin I monoclonal antibody. For reference,

found to be responsible for this low mobility $(14,19)$. In addition, in vitro translation and Western blot analysis of clone 3.4 with this 126 base pair deletion showed an electophoretic mobility identical to that of the $108 \mathrm{kD}$ isoform from the Hs578T cell line (Fig 10). Two of the breast cancers shown to overexpress amphiphysin I (Fig. 6) were also tested by RT-PCR and found to contain an identical 126 base pair deletion. the same samples in Fig. 5, lanes $\mathrm{c}$ and d appear in Fig. 6, lanes g and c, respectively. (B) The same blot as in $\mathrm{B}$ was probed with ${ }^{125} \mathrm{I}$-labeled protein $\mathrm{A}$ and a monoclonal antibody directed against the intermediate filament protein vimentin (arrowhead) to control for total protein loading. One and two asterisks correspond to the 128 and $108 \mathrm{kD}$ amphiphysin I immunoreactive bands, respectively.

We next investigated whether an amphiphysin I mRNA with a similar deletion is present in normal human tissues, thus accounting for the $108 \mathrm{kD}$ isoform present in these tissues. RT-PCR reactions performed on normal human heart, kidney, and mammary tissues revealed bands with a molecular weight identical to that seen in the Hs578T cell line. These bands were sequenced and found to contain the same 126 base

A
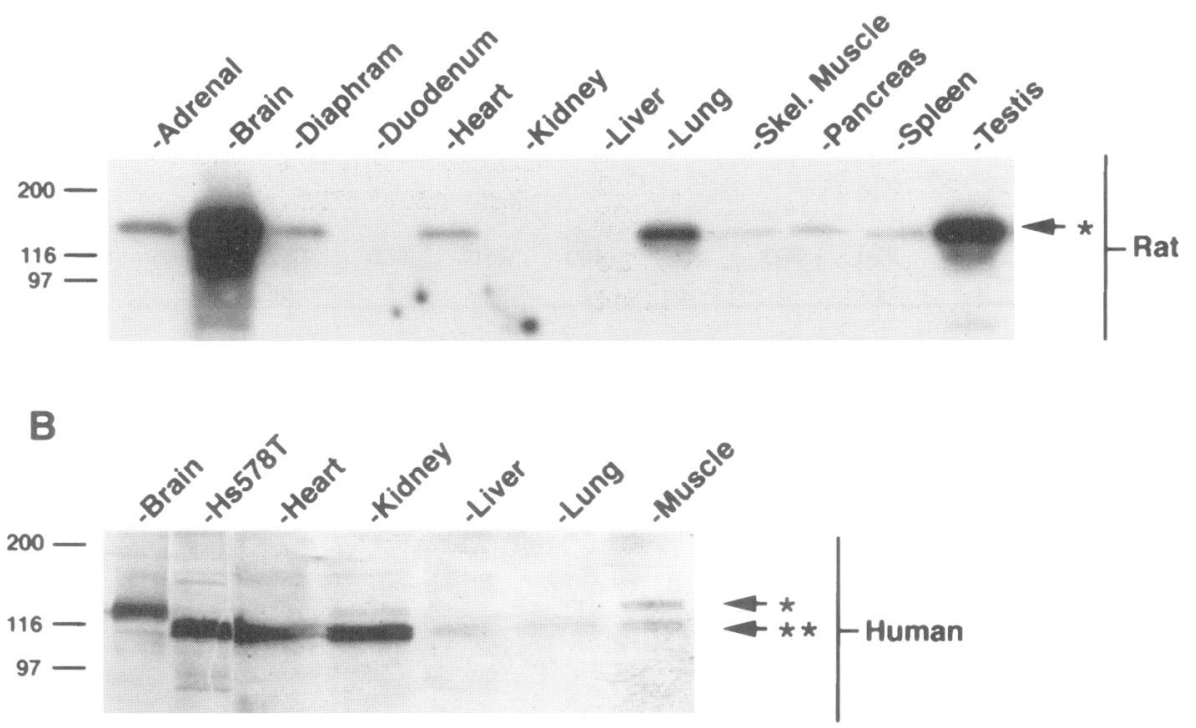

Fig. 7. Expression of amphiphysin I immunoreactivity in normal rat and human tissues. Total proteins of tissue homogenates were loaded in each lane and probed with monoclonal antibodies directed against domain $\mathrm{V}$ of amphiphysin I (see Fig. 3). Protein loaded was as follows: (A) rat tissues,
$100 \mu \mathrm{g} /$ lane; (B) human tissues, $10 \mu \mathrm{g}$ of brain homogenate, $100 \mu \mathrm{g}$ of the breast cancer cell line Hs578T, and $100 \mu \mathrm{g}$ of all other tissue homogenates. One and two asterisks point to the 128 and $108 \mathrm{kD}$ bands, respectively. 


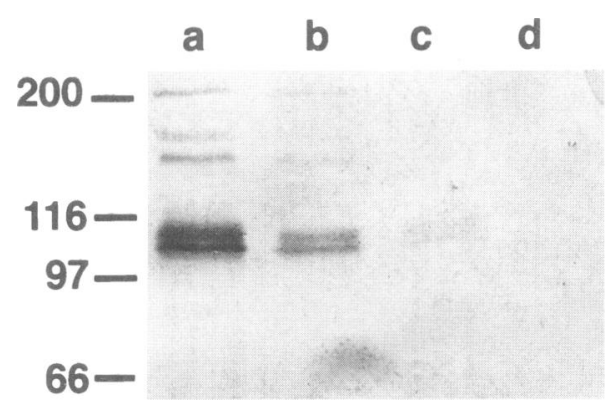

Fig. 8. The $108 \mathrm{kD}$ amphiphysin I band contains a functional SH3 domain. Affinity-chromatography of a Triton X-100 extract from the Hs578T cell line was performed using GST-fusion proteins. The following material was probed by Western blotting with monoclonal antibodies directed against amphiphysin I: (a) starting extract; (b) material affinity purified on the full-length proline-rich domain of dynamin I; (c) material affinity purified on a truncated proline-rich domain of dynamin I missing the amphiphysin I binding site (construct DynPRD 751 832 of ref. 22); (d) material affinity purified on GST alone.

pair deletion. Most likely, this deletion is the result of an alternative splicing event. We note that a homologous region undergoes alternative splicing in amphiphysin II (18-21).

\section{Discussion}

Amphiphysin I was implicated as the key autoantigen in stiff-man syndrome associated with breast cancer $(6,7)$ and subsequently as an au- toantigen in other paraneoplastic disorders of the central nervous system $(8,9)$. These disorders generally consist of various presentations of encephalomyelitis and the type of cancer varies, although in many cases, it is breast cancer ( $M$. Solimena, M. Butler, J. Dalmau [New York], F. Graus [Barcelona, Spain], J. Honnorat [Lyon, France], J. C. Antoine [Saint-Etienne, France], and P. Sillevis-Smitt [Rotterdam, The Netherlands], unpublished observations). One of the proposed mechanisms for the pathogenesis of these conditions is that cancer cells of the affected patients express a protein that is normally expressed only in the immunoprivileged environment of the central nervous system $(10,11,35)$. Expression of the amphiphysin I protein, however, has not been detected thus far in breast cancer $(7,8)$. Here we report high-level expression of amphiphysin I isoforms in the breast cancer tissue of a patient with high-titer anti-amphiphysin I autoantibodies and paraneoplastic sensory neuronopathy. These findings are consistent with a cause-effect relationship between abnormal expression of amphiphysin I in cancer and neurological disease, although the exact pathogenic mechanism remains to be elucidated. Since both amphiphysin I isoforms present in the cancer of the paraneoplastic patient are found in a variety of nonneuronal tissues, low-level amphiphysin I expression outside the brain seems insufficient to trigger autoimmunity. The trigger to anti-amphiphysin I autoimmunity could be enhanced expression of the antigen in the context of an inflammatory autoimmune reaction against the

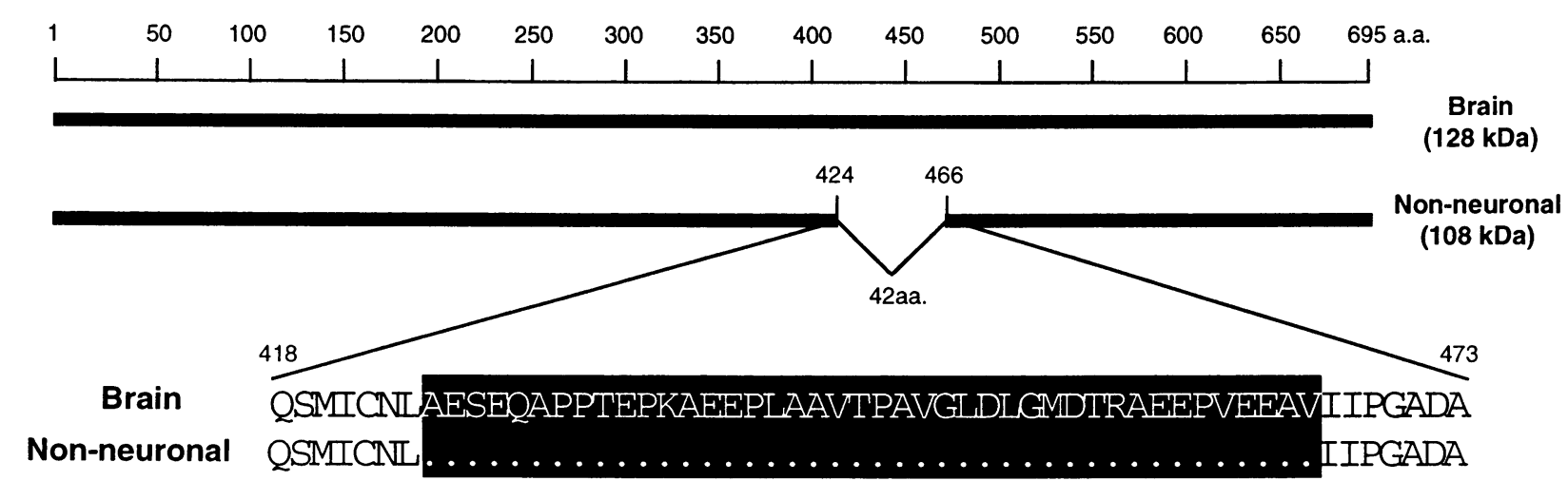

Fig. 9. Sequence comparison of amphiphysin I clone 3.4 from Hs578T cell line and human brain amphiphysin I. The schematic drawing illustrates the amino acid differences between the human brain isoform of amphiphysin I and the isoform encoded by clone 3.4 from a cDNA library of the
Hs $578 \mathrm{~T}$ breast cancer cell line. This 42 amino acid deletion was also detectable by RT-PCR in normal human kidney, heart, and mammary tissues, as well as in at least two of the breast cancers with highlevel amphiphysin I immunoreactivity in Fig. 6 above. 


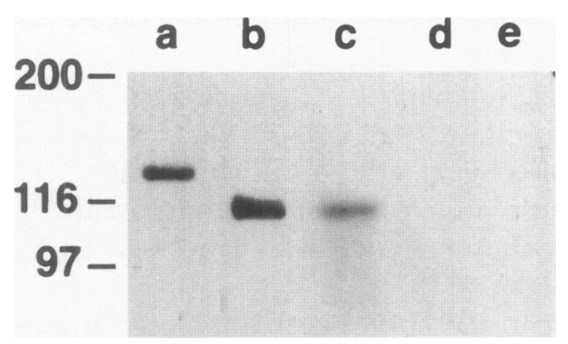

Fig. 10. In vitro transcription/translation of amphiphysin I clone 3.4. The following material was probed by Western blotting with a COOH-terminal directed anti-amphiphysin I monoclonal antibody: (a) human brain total protein homogenate; (b) Hs578T cell line total protein homogenate; (c) in vitro transcribed/translated product of clone 3.4 ; (d) in vitro transcribed/translated product of the luciferin CDNA; and (e) the product of an in vitro transcription/translation reaction in which no DNA was included.

tumor. Other predisposing factors, such as a specific HLA phenotype, may play a role in the development of autoimmunity. It is of interest that the breast cancer tissue of the patient with autoimmunity differed from the other cancer tissues we have examined in that it had higher levels of both the $128 \mathrm{kD}$ and $108 \mathrm{kD}$ amphiphysin I band.

A previous study has detected amphiphysin I mRNA in 5 of 14 breast cancer tissues by RT-PCR (8). However, considering our present identification of amphiphysin I expression in normal mammary tissue, it is the overexpression of the protein, rather than ectopic expression in mammary tissue, that seems characteristic of some breast cancers. That amphiphysin I mRNA was detected in 5 of 14 breast cancers in the previous study may reflect this overexpression as well (8). Both amphiphysin I and amphiphysin I mRNA had been detected in some small-cell lung carcinomas (8). The relationship between amphiphysin I expression and neoplastic growth in these latter tissues is unclear, as small-cell lung tumors have neuroendocrine properties and express significant levels of several neuronal proteins $(36,37)$.

The enhanced expression of amphiphysin I isoforms in some cancers may be an epiphenomenon of neoplastic transformation. On the other hand, the possibility that amphiphysin I may be more closely linked to neoplastic transformation should be considered. As previously proposed (14), a relationship of the amphiphysin protein family to the control of cell proliferation is sug- gested by yeast studies. Mutations of the two yeast genes that encode proteins with homology to amphiphysin I, the RVS161 and RVS167 genes, produce a phenotype characterized by reduced viability upon starvation $(12,13)$ in addition to defects in endocytosis, cell polarity, and actin function $(15,38)$. Reduced viability upon starvation can be explained by the inability of yeast cells to stop growing when exposed to unfavorable growth conditions and it suggests impairment of growth regulatory mechanisms. A similar phenotype is produced by mutations in the yeast homologue of the ras oncogene $(12,13)$.

Abnormal amphiphysin I expression may affect cell proliferation in mammalian cells through several mechanisms. Proteins of the amphiphysin family are thought to have pleotropic functions including roles in endocytosis $(2,3,21,38)$, actin function $(5,13,15,23,39)$ and cell growth control $(17,23)$. As a protein implicated in clathrin-mediated endocytosis, amphiphysin I may modulate signaling of growth factor receptors by regulating their internalization $(3,21,40)$. Alternatively, it may affect signal transduction from the cell surface by actions on the actin cytoskeleton $(5,38)$ or on protein-protein interaction cascades mediated through its SH3 domain $(23,41)$. Finally, a more direct potential role of amphiphysin family members in the regulation of cell proliferation is suggested by the identification of amphiphysin II isoforms as either MYC-interacting proteins with some properties of a tumor suppressor (17) or as CABLinteracting proteins (23). The finding that amphiphysin I is overexpressed, rather than underexpressed, in some cancers, is in contrast to a putative role of amphiphysin family members as negative regulators of cell growth. However, amphiphysin I overexpression, or the overexpression of a specific isoform, may have a dominant negative role. Amphiphysin I forms heterodimers with amphiphysin II (ref. 21 and our unpublished observations) and it was reported that over expression of amphiphysin I, but not concomitant overexpression of both amphiphysin I and II, has a dominant negative affect on clathrin-mediated endocytosis (21).

Irrespective of whether amphiphysin I expression in cancer cells is an event that lies upstream or downstream of neoplastic transformation, enhanced amphiphysin I-expression in some cancers and its implication in autoimmune paraneoplastic disease predict that further studies of this protein may aid in understanding important human diseases. 


\section{Acknowledgments}

We thank D. Stern (Yale), A. Perkins (Yale), and K. Tsutsui (Okayama, Japan) for discussion and J. Honnorat (Lyon, France), J. C. Antoine (SaintEtienne, France), P. Sillevis-Smitt (Rotterdam, The Netherlands), K. Schmierer (Berlin, Germany), and J. Dalmau (New York) for discussing their patients with us. We thank L. Gutierez and C. Howe (Yale) and C. R. Wenger (University of Texas Health Science Center at San Antonio) for help in obtaining human tissues. Some of the material used for this study was provided through the Yale Critical Technologies Service (Dr. C. Howe, Director), and through the National Breast Cancer Tissue Resource of the San Antonio SPORE (Specialized Program of Research Excellence). This work was supported in part by grants from the Human Frontier Science Program and NIH (CA46128 and NS36251) to P. D. C., by fellowships from Telethon and the Human Frontier Science Program to O. C., by a fellowship from the United States Army Medical Research and Development Command to C. D., by Grants-in-Aid for Scientific Research from the Ministry of Education, Science, Sports and Culture of Japan to K. T., and by NIH grant (P50 CA58183) to the National Breast Cancer Tissue Resource of the San Antonio SPORE.

\section{References}

1. Lichte B, Veh RW, Meyer HE, Kilimann MW. (1992) Amphiphysin, a novel protein associated with synaptic vesicles. EMBO J. 11: 2521-2530.

2. David C, McPherson PS, Mundigl O, De Camilli P. (1996) A role of amphiphysin in synaptic vesicle endocytosis suggested by its binding to dynamin in nerve terminals. Proc. Natl. Acad. Sci. U.S.A. 93: 331-335.

3. Shupliakov O, Low P, Grabs D, Gad H, Chen H, David C, Takei K, De Camilli P, Brodin L. (1997) Synaptic vesicle endocytosis impaired by disruption of dynamin-SH3 domain interactions. Science 276: 259-263.

4. Cremona O, De Camilli P. (1997) Synaptic vesicle endocytosis. Curr. Opin. Neurobiol. 7: 323-330.

5. Mundigl O, Ochoa G, David C, Slepnev V, Kabanov A, De Camilli P. (1997) Amphiphysin I antisense oligonucleotides inhibit neurite outgrowth in cultured hippocampal neurons. $\mathrm{J}$. Neurosci. 18: 93-103.

6. De Camilli P, Thomas A, Cofiell R, Folli F, Lichte B, Piccolo G, Meinck H, M, Austoni M, Fassetta G, Bottazzo G, Bates D, Cartlidge N, Solimena $M$, Kiliman MW. (1993) The synaptic vesicle-associated protein amphiphysin is the $128-\mathrm{kD}$ autoan- tigen of Stiff-Man syndrome with breast cancer. $J$. Exp. Med. 178: 2219-2223.

7. Folli F, Solimena M, Cofiell R, Austoni M, Tallini G, Fassetta G, Bates D, Cartlidge N, Bottazzo GF, Piccolo G, et al. (1993) Autoantibodies to a 128-kd synaptic protein in three women with the stiffman syndrome and breast cancer. $N$. Engl. J. Med. 328: $546-551$.

8. Dropcho EJ. (1996) Antiamphiphysin antibodies with small-cell lung carcinoma and paraneoplastic encephalomyelitis. Ann. Neurol. 39: 659-667.

9. Lennon VA, Manley HA, Kim K, Parisi JE, Kilimann MW, Benarroch EE. (1997) Amphiphysin autoantibodies: A paraneoplastic serological marker of breast and lung cancer-related encephalomyeloradiculoneuritides but not classical stiff-man syndrome. Neurology 48: A434.

10. Posner JB, Dalmau JO. (1997) Paraneoplastic syndromes affecting the central nervous system. Annu. Rev. Med. 48: 157-166.

11. Darnell RB. (1996) Onconeural antigens and the paraneoplastic neurologic disorders: At the intersection of cancer, immunity, and the brain. Proc. Natl. Acad. Sci. U.S.A. 93: 4529-4536.

12. Crouzet M, Urdaci M, Dulau L, Aigle M. (1991) Yeast mutant affected for viability upon nutrient starvation: Characterization and cloning of the RVS161 gene. Yeast 7: 727-743.

13. Bauer F, Urdaci M, Aigle M, Crouzet M. (1993) Alteration of a yeast SH3 protein leads to conditional viability with defects in cytoskeletal and budding patterns. Mol. Cell. Biol. 13: 5070-5084.

14. David C, Solimena M, De Camilli P. (1994) Autoimmunity in Stiff-Man syndrome with breast cancer is targeted to the C-terminal region of human amphiphysin, a protein similar to the yeast proteins, Rvs167 and Rvs161. FEBS Lett. 351: 73-79.

15. Sivadon P, Bauer F, Aigle M, Crouzet M. (1995) Actin cytoskeleton and budding pattern are altered in the yeast rvsl61 mutant: The Rvs161 protein shares common domains with the brain protein amphiphysin. Mol. Gen. Genet. 246: 485495.

16. Sparks AB, Hoffman NJ, McConnell SJ, Fowlkes DM, Kay BK. (1996) Cloning of ligand targets: Systemic isolation of SH3 domain-containing proteins. Nature Biotech. 14: 741-744.

17. Sakamuro D, Elliott KJ, Wechsler-Reya R, Prendergast GC. (1996) BIN1 is a novel MYC-interacting protein with features of a tumour suppressor. Nature Genet. 14: 69-77.

18. Leprince C, Romero R, Cussac D, Vayssiere B, Berger R, Tavitian A, Camonis JH. (1997) A new member of the amphiphysin family connecting endocytosis and signal transuction pathways. J. Biol. Chem. 272: 15101-15105.

19. Butler MH, David C, Ochoa GC, Freyberg Z, Daniell L, Grabs D, Cremona O, De Camilli P. (1997) Amphiphysin II (SH3P9; BIN1), a member of the amphiphysin/RVS family, is localized in the 
cortical cytomatrix of axon initial segments and nodes of Ranvier in brain and around T-tubules in skeletal muscle. J. Cell Biol. 137: 1355-1367.

20. Tsutsui K, Maeda Y, Tsutsui K, Seki S, Tokunaga A. (1997) cDNA cloning of a novel amphiphysin isoform and tissue-specific expression of its multiple splice variants. Biochem. Biophys. Res. Commun. 236: 178-83.

21. Wigge $P$, Kohler $K$, Vallis $Y$, Doyle CA, Owen D, Hunt SP, McMahon HT. (1997) Amphiphysin heterodimers: potential role in clathrin-mediated endocytosis. Mol. Biol. Cell 8: 2003-2015.

22. Ramjaun AR, Micheva KD, Bouchelet I, McPherson PS. (1997) Identification and characterization of a nerve terminal-enriched amphiphysin isoform. J. Biol. Chem. 272: 16700-16706.

23. Kadlec L, Pendergast AM. (1997) The amphiphysin-like protein 1 (ALPl) interacts functionally with the $C A B L$ tyrosine kinase and may play a role in cytoskeletal regulation [In Process Citation]. Proc. Natl. Acad. Sci. U.S.A. 94: 12390-12395.

24. McPherson PS, Garcia EP, Slepnev VI, David C, Zhang XM, Grabs D, Sossin WS, Bauerfeind R, Nemoto Y, De Camilli P. (1996) A presynaptic inositol-5-phosphatase. Nature 379: 353-357.

25. Grabs D, Slepnev VI, Songyang Z, David C, Lynch M, Cantley LC, De Camilli P. (1997) The SH3 domain of amphiphysin binds the proline-rich domain of dynamin at a single site that defines a new SH3 binding consensus sequence. J. Biol. Chem. 272: 13419-13425.

26. De Camilli P, Cameron R, Greengard P. (1983) Synapsin I (protein I) a nerve terminal specific phosphoprotein. Its general distribution in synapses of the central and peripheral nervous system demonstrated by immunofluorescence in froxen and plastic sections. J. Cell Biol. 96: 1337-1354.

27. Navone F, Jahn R, Di Gioia G, Stukenbrok H, Greengard P, De Camilli P. (1986) Protein p38: An integral membrane protein specific for small vesicles of neurons and neuroendocrine cells. J. Cell Biol. 103: 2511-2527.

28. Jahn R, Schiebler W, Ouimet C, Greengard P. (1985) A 38,000-dalton membrane protein (p38) present in synaptic vesicles. Proc. Natl. Acad. Sci. U.S.A. 82: 4137-4141.

29. Kohler G, Milstein C. (1975) Continuous cultures of fused cells secreting antibody of predefined specificity. Nature 256: 495-497.

30. Hackett AJ, Smith HS, Springer EL, Owens RB, Nelson-Rees WA, Riggs JL, Gardner MB. (1977)
Two syngeneic cell lines from human breast tissue: the aneuploid mammary epithelial (Hs578T) and the diploid myoepithelial (Hs578Bst) cell lines. J. Natl. Cancer Inst. 58: 1795-806.

31. Chirgwin JM, Przybyla AE, MacDonald RJ, Rutter WJ. (1979) Isolation of biologically active ribonucleic acid from sources enriched in ribonuclease. Biochemistry 18: 5294-5299.

32. Bogue CW, Gross I, Vasavada H, Dynia DW, Wilson CM, Jacobs HC. (1994) Identification of Hox genes in newborn lung and effects of gestational age and retinoic acid on their expression. Am. J. Physiol. 266: L448-454.

33. Laemmli UK. (1970) Cleavage of structural proteins during the assembly of the head of bacteriophage T4. Nature 227: 680-685.

34. Towbin H, Staehelin T, Gordon J. (1979) Electrophoretic transfer of proteins from polyacrylamide gels to nitrocellulose sheets: Procedure and some applications. Proc. Natl. Acad. Sci. U.S.A. 76: 43504354.

35. Dalmau J, Graus F, Cheung NK, Rosenblum MK, Ho A, Canete A, Delattre JY, Thompson SJ, Posner JB. (1995) Major histocompatibility proteins, anti-Hu antibodies, and paraneoplastic encephalomyelitis in neuroblastoma and small cell lung cancer. Cancer 75: 99-109.

36. Wiedenmann B, Huttner WB. (1989) Synaptophysin and chromogranins/secretograninsWidespread constituents of distinct types of neuroendocrine vesicles and new tools in tumor diagnosis. Virchows Arch. B Cell. Pathol. Incl. Mol. Pathol. 58: 95-121.

37. Williams CL. (1997) Basic science of small cell lung cancer. Chest Surg. Clin. North Am. 7: 1-19.

38. Bauerfeind R, Takei K, De Camilli P. (1997) Amphiphysin $I$ is associated with coated endocytic intermediates and undergoes stimulation-dependent dephosphorylation in nerve terminals. J. Biol. Chem. 272: 30984-30992.

39. Munn AL, Stevenson BJ, Geli MI, Riezman H. (1995) end5, end6, and end7: Mutations that cause actin delocalization and block the internalization step of endocytosis in Saccharomyces cerevisiae. Mol. Biol. Cell 6: 1721-1742.

40. Vieira AV, Lamaze C, Schmid SL. (1996) Control of EGF receptor signaling by clathrin-mediated endocytosis. Science 274: 2086-2089.

41. Pawson T. (1995) Protein modules and signalling networks. Nature 373: 573-580. 